Int. J. Dev. Biol. 53: 45-57 (2009)

doi: $10.1387 / \mathrm{ijdb} .082669 \mathrm{cp}$

\title{
Hedgehog signalling is required for cloacal development in the zebrafish embryo
}

\author{
CAROLINE A. PARKIN ${ }^{1,2}$, CLAIRE E. ALLEN ${ }^{1}$ and PHILIP W. INGHAM*,1,2 \\ ${ }^{1}$ MRC Centre for Developmental \& Biomedical Genetics, University of Sheffield, Firth Court, Western Bank, Sheffield, U.K. and \\ ${ }^{2}$ Institute of Molecular and Cell Biology, Proteos, Singapore
}

\begin{abstract}
The Hedgehog (Hh) family of signalling molecules is essential for a wide range of developmental processes. Mammalian studies have implicated the Hedgehog pathway in the aetiology of anorectal malformations (ARMs), relatively common congenital anomalies caused by failures in the development of the cloaca. In this study we demonstrate that Hh signalling is absolutely required for the formation of the zebrafish cloaca and that the severity of the posterior gut abnormalities induced by a reduction in Hh activity is dependent on the levels of Hh signal transduction. The complete loss of all Hh activity results in the most severe defects and the critical period for Hh activity is between 34 and 74 hours post fertilisation. Using a range of mutant genotypes that cause notochord and floorplate abnormalities, we show that the source of the Hh signals required for posterior gut formation is the endoderm and not the notochord, as previously postulated in mammalian models of ARMs. We show that Adriamycin, a drug known to cause ARMs in rat, but not chick embryos, has no effect on the development of the zebrafish gastrointestinal tract. These studies establish the zebrafish as a model for ARMs, and for the elucidation of other pathways involved in hindgut developmental processes.
\end{abstract}

KEY WORDS: zebrafish, sonic hedgehog, gut, anorectal malformations, cloaca, stenosis, Adriamycin

\section{Introduction}

The mechanisms involved in the development of the vertebrate distal hindgut are yet to be fully elucidated. The majority of studies to date have focused on the morphology of the hindgut in mouse and human and observations of gene expression in the hindgut have, for the most part, not been accompanied by analyses of the corresponding gene function in hindgut development. Some studies in mammalian models have, however, demonstrated a role for Sonic Hedgehog (Shh) and Fibroblast growth factor 10 (Fgf10). Mice mutant for either of these genes exhibit hindgut malformations similar to those observed in human pathologies. Additionally, Hh mutants display hyperplasia of the bladder and genitals (Fairbanks et al., 2004, Haraguchi et al., 2000, Kimmel et al., 2000, Mo et al., 2001, Sasaki et al., 2004b).

Anorectal malformations (ARMs) in humans encompass a variety of defects of the rectum, urinary and reproductive tracts with varying degrees of complexity and severity. The commonest and least severe defect is anal stenosis - the narrowing of the anal opening. More severe is the imperforate anus, which has an incidence of around 1 in 5000 (Mo et al., 2001). Those born with imperforate anus have no anal opening at all, and instead a fistula (channel) may form between the rectum and an adjacent structure. Alternatively the rectum may end as a blind pouch, which is called atresia. The most severe and rare malformation in the spectrum, occurring in 1 in 50,000 births (Mo et al., 2001), is the persistent cloaca, where a single perineal orifice is formed due to the confluence of the rectum, vagina and urethra into a common channel.

Individuals with ARMs often have abnormalities in other organ systems. Currently the pathogenesis and aetiology of these defects and the association between them is poorly understood. Malformation of the anus is associated with several congenital syndromes, including Townes-Brocks, PallisterHall, and Currarino syndromes, and the VACTERL (Vertebral, Anal, Cardiac, Tracheoesophageal, Renal and Limb) associa-

Abbreviations used in this paper:ARM, anorectal malformation; Hh, hedgehog; hpf, hours post fertilization; Shh, sonic hedgehog; VACTERL, vertebral, anal, cardiac, tracheosophageal, renal and limb.

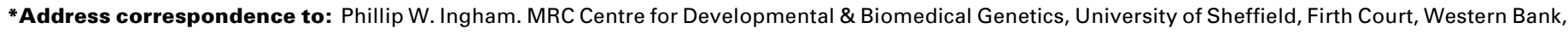
Sheffield, S102TN, U.K. Fax: +44-114-276-5413. e-mail: p.w.ingham@sheffield.ac.uk
} 
$24 \mathrm{hpf}$

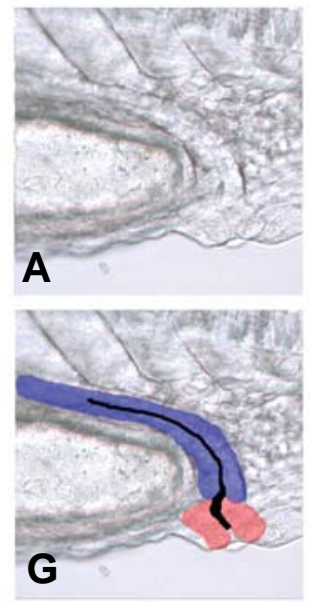

hindgut

proctodeum/cloaca

pronephric duct
$48 \mathrm{hpf}$
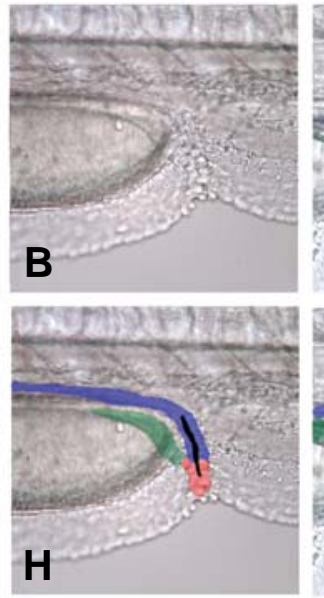

$60 \mathrm{hpf}$
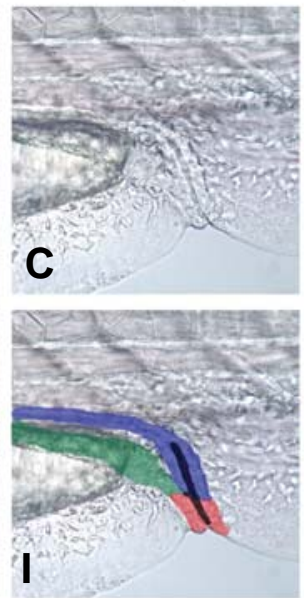

$72 \mathrm{hpf}$
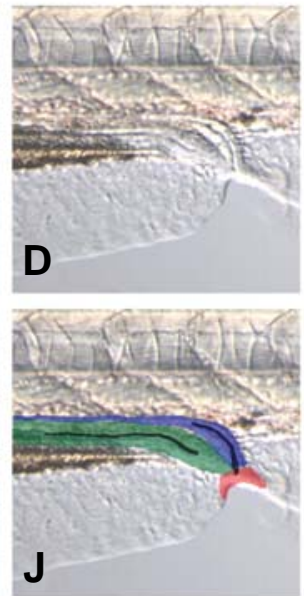

$96 \mathrm{hpf}$
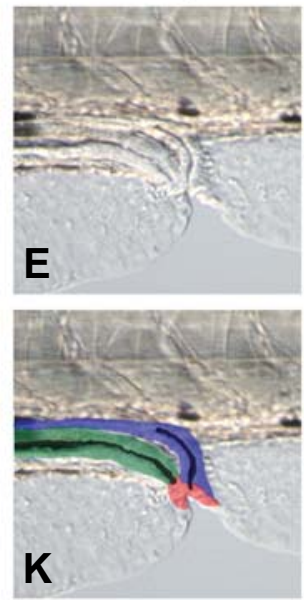

$120 \mathrm{hpf}$
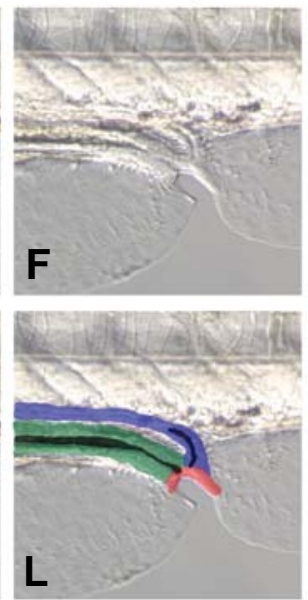

Fig. 1. The development of the cloaca in WT embryos. (A-E) Live WT embryos between 24 and 120 hpf. At $24 \mathrm{hpf}$ the proctodeum is visible as a mass of cells at the site of the pronephric opening. The proctodeum surrounds the opening of the pronephric duct at all stages and forms the cloaca. By 48 hpf the posterior gut has reached the cloaca and starts to fuse with it. As the posterior gut becomes canalised from anterior to posterior, the proctodeum invaginates to form the anus. The anal canal, the most distal part of the gastrointestinal tract, is formed by the fusion of the proctodeum with the posterior gut endoderm. By $\sim 96$ hpf the posterior gut lumen is in contact with the ventral edge of the embryo, but is not yet open. At 120 hpf the gastrointestinal tract opens externally, adjacent to the pronephric duct. (G-L) Live WT embryos between 24 and 120 hpf with an overlay showing the identity of various tissues: green, posterior gut; blue, pronephric ducts; red, proctodeum/cloaca.

tion (Belloni et al., 2000, Hagan et al., 2000, Hall et al., 1980, Kohlhase et al., 1998, Martinez-Frias et al., 2001, Rittler et al., 1996, Ross et al., 1998).

Animal models for various digestive system malformations have been developed to investigate their genetic and environmental basis. Previous studies in mammals have shown that $S h h$ and its downstream mediators play an important role in early hindgut specification (Bitgood and McMahon, 1995, Wells and Melton, 1999). Shh and Gli deficient mice display various VACTERL-like abnormalities, including hindgut malformations such as imperforate anus and anal stenosis (Kim et al., 2001, Kimmel et al., 2000, Mo et al., Ramalho-Santos et al., 2000).

Prenatal exposure of foetal rats to the drug Adriamycin induces various malformations similar to those seen in the VACTERL association, providing a model that has been used extensively to investigate the various anomalies including the consistently occurring ARMs (Gillick et al., 2003, Kolker et al., 2000, Millar et al., 2001, Mortell et al., 2004). Several studies have shown that the expression of $S h h$ is altered in the Adriamycin treated rats (Arsic et al., 2004, Arsic et al., 2003, Spilde et al., 2003). In the foregut Shh expression is reduced and eventually lost when rats are treated with Adriamycin, whilst expression of Shhin the notochord is maintained (Arsic et al., 2004). The notochord is, however, abnormal in these rats and may remain attached to the gut, or may bifurcate producing ectopic notochord. Interestingly, the increased volume of notochord per embryo means there is a relative increase in Shhexpression compared to control rats (Arsic et al., 2004). It has been speculated that the altered notochord in the treated rats is responsible for some of the VACTERL anomalies, including the ARMs, either due to changes in Shh expression or unknown changes in factors normally secreted from the notochord (Gillick et al., 2003, Qi et al., 2003). In contrast to the consistent ARMs seen in foetal rats exposed to Adriamycin, no anal defects were detectable in similarly treated chick embryos (Mortell et al., 2003).

Recently Pyati etal. (2006) presented the first detailed description of zebrafish cloacal development and demonstrated an early requirement for Bmp signalling in specification of the presumptive cloaca. Fish deficient in Bmp activity have defects in the opening of the pronephric ducts (kidney terminus) and the posterior gut, which was attributed to an overall failure in the external opening of the cloaca. The role of other genetic pathways in zebrafish cloacal formation has not been studied.

Here we analyse cloacal development in zebrafish embryos deficient in $\mathrm{Hh}$ activity. The zebrafish offers unique advantages over amniote models of vertebrate development due to its external fertilisation and optically clear embryos, allowing the visualisation of gastrointestinal development at all stages in living animals.

To examine the role of the $\mathrm{Hh}$ pathway in posterior gut development we used mutants in smoothened (smo), shha, ihha and gli2a as well as various mutants affecting notochord development that have either increased or decreased levels of midline $\mathrm{Hh}$ activity. To determine the temporal requirement for Hh activity we used the Hh pathway antagonist cyclopamine. The posterior guts of embryos with defective notochords were largely unaffected. Global reduction in Hh pathway activity, however, resulted in a spectrum of ARMs similar to that seen in humans, with the severity of the abnormality correlating with the residual level activity of the pathway, the most severe defects occurring in embryos devoid of all activity.

\section{Results}

The earliest arising part of the zebrafish cloaca is the proctodeum, which eventually becomes the caudal most part of the 
gastrointestinal tract (i.e. the anus); it also encircles the adjacent pronephric opening (Fig. 1). The proctodeum initially has a very narrow orifice, but between 60 and $96 \mathrm{hpf}$ this opens out to form an inverted U-shape that surrounds a gap in the ventral fin (which must develop to create an opening for the urorectal structures) (Fig. 1C-E). The pronephric ducts open externally at the position of the proctodeum around $24 \mathrm{hpf}$ (Kimmel et al., 1995). At this stage, the posterior gut is a mass of endodermal cells, slightly anterior to the pronephric ducts. During the following 3-4 days of development, the endoderm arranges itself into a rod (Field et al., 2003) (Fig. 1B-F). A lumen develops, advancing posteriorly from the midgut, until $96 \mathrm{hpf}$, at which point the lumen has reached the end of the posterior gut and is only closed by the proctodeum/anus (Fig. 1E). Opening of the gastrointestinal tract is not completely synchronised between embryos in the same clutch. It occurs at some point between the 4th and 5th day of development, when the controlled excretion of faeces (or injected fluorescent dye) is visible in live embryos (data not shown).

\section{Hh pathway genes are expressed in the developing zebrafish posterior gut}

The zebrafish has multiple Hh homologs (Ekker et al., 1995, Krauss et al., 1993), including three that are expressed in the gut endoderm. The expression of shhaand shhbin the zebrafish foregut and midline tissues has been described previously (Roy et al., 2001, Strahle etal., 1996), however, these studies did not address expression of $\mathrm{Hh}$ pathway components in the posterior gut and surrounding tissues. Expression of shha, but not shhb, is detected in the developing posterior gut and proctodeum from around $24 \mathrm{hpf}$ (Fig. 2A) (shhb data not shown). Expression of shha in the posterior tip of the gut persists until at least 120 $\mathrm{hpf}$, with transcripts becoming restricted to scattered cells in the endodermal layer (Fig. 2B, C). A third Hh gene, ihha, is first detectable at 12-14 somites in the developing proctodeum (Qiao, 1997; data not shown). This expression continues throughout development, with the signal being weakly maintained in the putative anal region at $24 \mathrm{hpf}$, and more strongly from $48 \mathrm{hpf}$ onwards in the posterior gut and cloaca (Fig. 2D-F). Expression of the genes encoding the $\mathrm{Hh}$ receptor (ptc1), and transcriptional effector (gli2a) is detected in the surrounding mesenchyme (Fig. 2G-L).

\section{Shha and Smo mutant fish have cloacal abnormalities}

To assess the role of $\mathrm{Hh}$ signalling in cloacal development, we analysed the phenotypes of fish mutant for smoothened (smu $\left.{ }^{h 641}\right)$, shha (syut4, syu ${ }^{\text {bx392, syu }}{ }^{\text {bq70 }}$ )or ihhahu3121 (Barresi et al., 2000, Schauerte et al., 1998). Live DIC imaging allows good visualisation of zebrafish cloacal morphology but further structural details are revealed with confocal scans of actin (FITC-Phalloidin) and nuclear staining (propidium iodide; henceforth called A-PI staining). To investigate the functionality of the digestive system embryos were injected into the pericardial sac with a fluorescein salt that accumulates in the embryonic gut and is visibly excreted once the gastrointestinal tract is functional (as per comm. Leila Abbas). In cases of imperforate anus, the dye fails to be excreted and remains within the gut.

The smumutant exhibits the most severe anal phenotype of all the Hh pathway mutants studied. The pronephric ducts appear to be positioned correctly at $120 \mathrm{hpf}$, although they are slightly disorganised (compare WT in Fig. 3A-C to smu in Fig. $3 \mathrm{E}-\mathrm{G}$ ). The proctodeum invaginates to form the anal canal, but it fails to open out into a characteristic inverted U-shape. Additionally, the posterior gut itself is poorly developed. Examination with A-PI staining confirms that smu embryos have a very narrow posterior gut, with little musculature evident (Fig. $3 G)$. The A-PI staining also revealed that the posterior gut never fuses with the proctodeum, and instead ends blindly (atresia) in all embryos examined (Fig. 3G, H). Fluorescent dye injection supports this observation, as all the embryos examined were imperforate $(100 \%, 40 / 40$; Fig. $3 \mathrm{H})$. It should be noted that peristalsis was not always detected in living smuembryos. It is

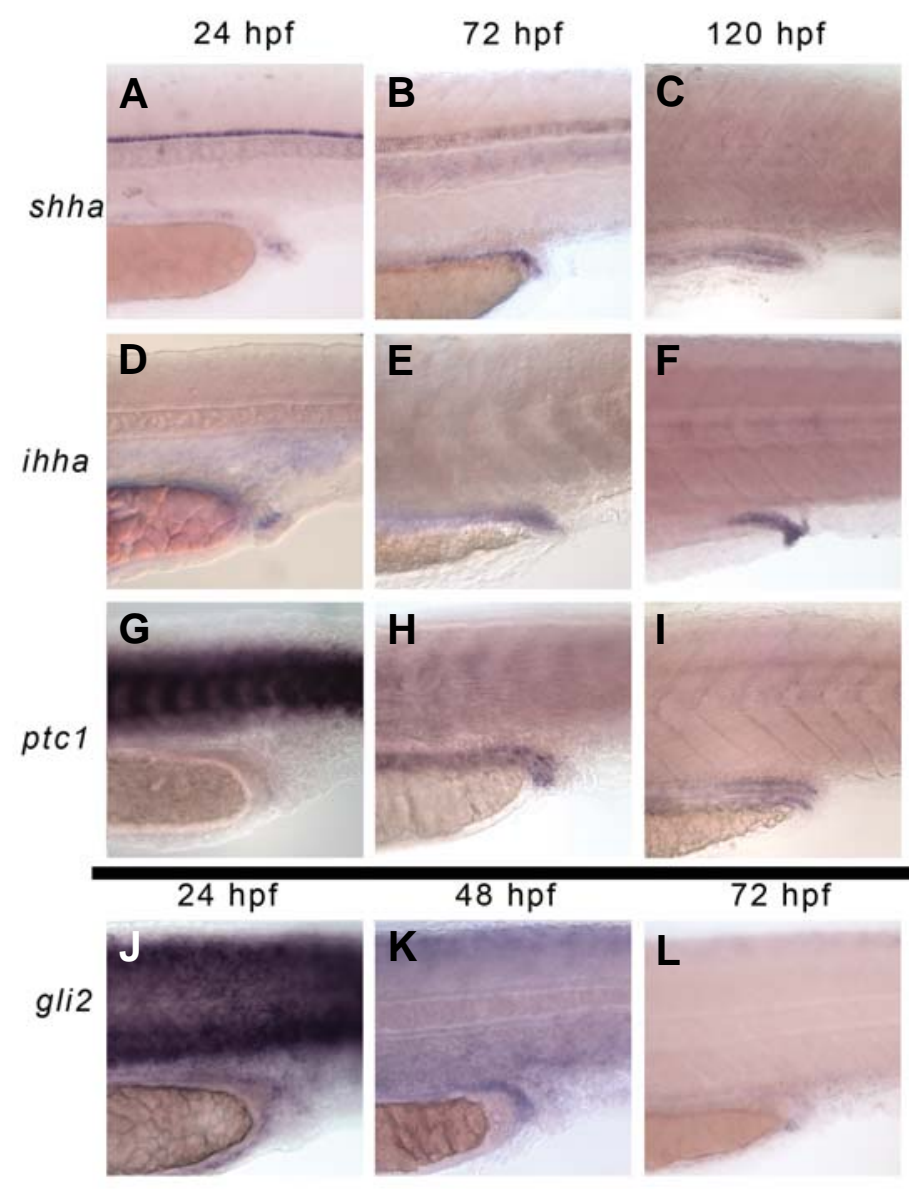

Fig. 2. Expression pattern of $\boldsymbol{H h}$ genes in the developing cloaca. In situ hybridisation stains in WT embryos. (A-C) Transcripts for shha are detected at low levels in the posterior gut endoderm and persist until at least $120 \mathrm{hpf}$. (D-F) ihha is expressed in the proctodeum from $24 \mathrm{hpf}$ and is expressed in the posterior gastrointestinal tract and proctodeum until at least $120 \mathrm{hpf}$. (G-H) Before $48 \mathrm{hpfptc} 1$ transcripts are not up-regulated in the area surrounding the posterior gut, but later ptc1 is expressed at higher levels in the mesodermal layer that surrounds the Hh expressing endoderm. (J-L) At 24 hpf gli2a is expressed in a diffuse pattern around the developing posterior gut, around 48 hpf gli2a expression in the developing posterior gut is at its strongest, with low-level expression on the posterior edge of the pronephric ducts, but not within them. By $72 \mathrm{hpf}$ gli2a is expressed in cells surrounding the anal sphincter, and weakly in a large diffuse area around the urorectal opening. gli2a expression is not detectable in the urorectal region after $96 \mathrm{hpf}$. 
Fig. 3. Hh signalling is essential for cloacal development. Bright field images of live Hh pathway mutants and WT siblings $(\mathbf{A}, \mathbf{B}, \mathbf{E}, \mathbf{F}, \mathbf{I}, \mathbf{J}, \mathbf{M}, \mathbf{N})$ and confocal scans of embryos stained with $\alpha$-actin-phalloidin (green) and propidium iodide (red) at $120 \mathrm{hpf}(\mathbf{C}, \mathbf{G}, \mathbf{K}, \mathbf{0})$. Live embryos were injected with fluorescein salt at 72-96 hpf, which accumulates in the gut prior to the opening of the gastrointestinal tract and is then excreted once the gut is functional. Brightfield/fluorescent image merge with the fluorescent channel only shown in the inset $(\mathbf{D}, \mathbf{H}, \mathbf{L}, \mathbf{P})$. The overlay in $(\mathbf{B}, \mathbf{F}, \mathbf{I}, \mathbf{N})$ shows the approximate identity of the relevant tissues, with the posterior gut in green and pronephric ducts in blue. (A,B) WT. By 120 hpf the gastrointestinal tract has fused with the proctodeum and has an independent opening, adjacent to the pronephric ducts. (C) WT. The pronephric ducts have a single narrow opening slightly caudal to the posterior gut. The position where the ducts join is visible in the confocal cross section as an upturned ' $U$ ' shape, with the anterior ducts out of the plane of focus. The posterior gut is surrounded by smooth muscle, and ends with an anal sphincter that is only slightly narrower then the preceding gut. (D) WT embryo excreting fluorescent dye. (E,F) smu. The pronephric ducts are present and are likely to be functional, but the posterior gut is not visible, due to the shape of the embryo and folding of the ventral fins. (G) smu. The pronephric duct caudal to the point where the left and right ducts fuse is much longer in smu mutants because the proctodeum has not opened out. The posterior gut tries to fuse with the proctodeum, but fails, resulting in atresia. (H) smu embryos are completely imperforate (100\%, 40/40) and lack peristaltic movement. Application of gentle pressure to the gut moves the dye to the end of the gastrointestinal tract, where it is clear that it is blocked and imperforate. (I, J) syu ${ }^{t 4}$ (shha). A channel apparently common between the posterior gut and pronephros (arrow) is suggestive of a fistula between them, but it seems the gut does not fuse correctly with the cloaca leading to imperforate anus. (K) syu ${ }^{t 4}$. The posterior gut of syu ${ }^{t 4}$ embryos ends blindly dorsal to the proctodeum in most casese. Frequently there is an abortive attempt to fuse with the cloaca leading to the appearance of a fistula between the posterior gut and pronephric duct (arrow). The gastrointestinal tract is completely imperforate-even in instances when there appears to be a fistula. (L) syu ${ }^{t 4}$ embryo with imperforate anus/atresia; fluorescent dye can be seen at the blocked end of the gastrointestinal tract in all embryos (100\%, 49/49). (M,N) yot (gli2). The pronephric ducts appear to be functional, but are slightly distorted. The gastrointestinal tract is imperforate having failed to fuse with the proctodeum. In this instance peristaltic movements have created a pressure buildup in the distal gastrointestinal tract, causing an outward bulge. (0) yot. The pronephric ducts join together in the correct position, but the usually short single duct appears slightly longer then normal due to the proctodeum failing to open. The posterior gut turns ventrally towards the proctodeum, but fails to fuse with it fully, instead ending blindly adjacent to the pronephric opening. Additionally there is a large reduction in gut girth, probably due to a reduction in smooth muscle in the caudal gut. (P) yot. The majority of yot embryos are imperforate (83\%, 15/18), but in the embryos shown here, dye is excreted from the gut through a narrow opening, which is the equivalent of anal stenosis.

likely that this would greatly contribute to the failure of the fluorescein to be excreted. In recently euthanized WT embryos, where peristalsis has stopped, it is possible to force open the gut and induce fluorescein excretion by applying gentle pressure with a blunt needle to the fore or midgut. Such 'forced' excretion is not possible in smu mutants, indicating that the gastrointestinal tract is completely imperforate.

The complete loss of Shha activity in the syu ${ }^{t 4}$ mutant results in anorectal malformations similar to, though less severe than, those observed in smumutants. As in smumutants, the pronephric ducts appear to develop normally but the proctodeum does not open into an upturned U-shape (Fig. 3I, J). The proctodeum remains closed at its ventral edge, as a consequence of which the gastrointestinal tract seems to fuse with the pronephric ducts; this results in what appears to be a fistula, visible in both live and fixed embryos (arrow in Fig. 31$\mathrm{K})$. Injection of fluorescein into live $s y u^{t 4}$ embryos, reveals that the gut is imperforate, as no excretion of fluorescein is detectable (49/49; Fig. 3L). Embryos mutant for the moderate hypomorphic allele, syu ${ }^{b \times 392}$, have a phenotype similar to syu ${ }^{t 4}$, although slightly less severe; only a third are imperforate (4/ 12 ), with the remainder exhibiting anal stenosis $(8 / 12)$ (data not shown). Embryos homozygous for the weak hypomorphic allele $s y u{ }^{b q 70}$ allele display a variable phenotype. Nearly half the embryos develop a functional and perforate anus (21/39), and a further third are perforate, but exhibit anal stenosis (12/39), while in the remaining $15 \%(6 / 39)$ of embryos the phenotype is similar to that observed in $s y u^{t 4}$ mutants, with complete atresia (data not shown).

Embryos homozygous for an ENU induced point mutation in ihha do not exhibit ARMs and are indistinguishable from their WT siblings (data not shown). Simultaneous homozygosity for this ihha allele and $\mathrm{syu}^{t 4}$ did not increase the severity of the syu ${ }^{t 4}$ phenotype (data not shown). 
In the chick embryo, expression of bmp4 in the hindgut is regulated by $\mathrm{Hh}$ signalling. To explore whether a similar relationship underlies the Hh mutant phenotypes in zebrafish, we analysed the expression of bmp4 by in situ hybridisation. No changes were seen in the levels of expression in smu or syu mutants (Fig. 4E-G, I-K). By contrast, expression of ptc1, a known target of the Hh pathway is lost in the posterior gut of $s m u$ mutants (Fig. 4H), although it persists in syumutants (Fig. 4L). Cloacal expression of evx1 and prdm1 is lost embryos with impaired BMP signalling (Pyati et al., 2006) whereas in syuand smu mutants it persists, highlighting the altered shape of the cloaca in both mutants (Fig. 5).

\section{A dominant repressor form of Gli2a interferes with anorec- tal development}

The you-too ${ }^{\text {ty11 }}$ (yot) mutation results in expression of a Cterminal truncated Gli2a protein that is unable to activate transcription but instead functions as a constitutive repressor of Hh target genes (Karlstrom et al., 2003). yot mutant embryos have severe anorectal defects. The gastrointestinal tract is imperforate in most cases, though as in syu and smumutants, the pronephric ducts appear to be largely unaffected (Fig. 3M, $\mathrm{N})$. In the embryo shown in Fig. 3M, pressure has built up in the gut due to peristaltic movements, causing the posterior gut to become distended. Examination with A-PI also shows an imperforate phenotype and highlights the thin posterior gut walls, which lack thick smooth muscle (Fig. 30). Fluorescent dye injection demonstrates that most yot embryos are imperforate (15/18), while those that are perforate have anal stenosis (3/18; Fig. 3P). By contrast, embryos homozygous for the dtr mutation, which disrupts zebrafish glit, show no anorectal defects were and have normal perforate gastrointestinal tracts (data not shown).

\section{Hh dysfunction does not affect apopto- sis in the urorectal region}

TUNEL stains of WT embryos reveal specific apoptotic events in the proctodeum between 24 and 120 hpf (Fig. 6A-E), suggesting that programmed cell death is required for urorectal morphogenesis. TUNEL staining in syu and smu embryos did not reveal any dramatic changes in the levels or distribution of cell death in the posterior gut area (Fig. 6F-P). Counts of apoptotic cells performed at various time points show that the level of cell death varies considerably between fish but there was no significant difference between the mutant and WT embryos (Fig. 6P). By contrast, we observed a massive increase in cell death in the neural tube of mutant embryos, most noticeably at $24 \mathrm{hpf}$ (Fig. 6A compared to Fig. 6F, $\mathrm{K})$ consistent with previous reports (Chen et al., 2001).

\section{Cyclopamine mediated knockdown of Hh signalling re- veals temporal requirements during posterior gut develop- ment}

To investigate the temporal requirements for Hh signalling during posterior gut development, we used the alkaloid cyclopamine to inhibit the activity of Smo (Fig. 7). Exposure to cyclopamine, (followed by its subsequent washing out before $24 \mathrm{hpf}$ ) caused U-shaped somites and ventral body curvature, a phenotype typical of fish with reduced $\mathrm{Hh}$ activity, but did not induce any strong ARMs. Exposure of embryos to $25 \mu \mathrm{M}$ cyclopamine from 24 to $48 \mathrm{hpf}$, resulted in some embryos with ARMs (Fig. 7A-D). The posterior gut looked disorganised in both live embryos and those stained with A-PI (Fig. 7A-C) and there appeared to be a single outlet for both the gastrointestinal tract and pronephric duct (Fig. 7C). Injection with fluorescein revealed that a quarter had imperforate anus (4/12; Fig. 7D). In embryos treated between 34 and 74 hpf a fistula frequently developed between the gastrointestinal tract and pronephric ducts, which is clearly visible at $120 \mathrm{hpf}$ in live and A-PI stained embryos (Fig. 7E, F, G). A large number of the embryos that had a single channel for the gastrointestinal tract and pronephric duct were imperforate. Fluorescein was pushed into the pronephric ducts, an effect never observed in WT embryos or those treated between 24 and 48 hpf (compare Figs. 3D, 7D to Fig.

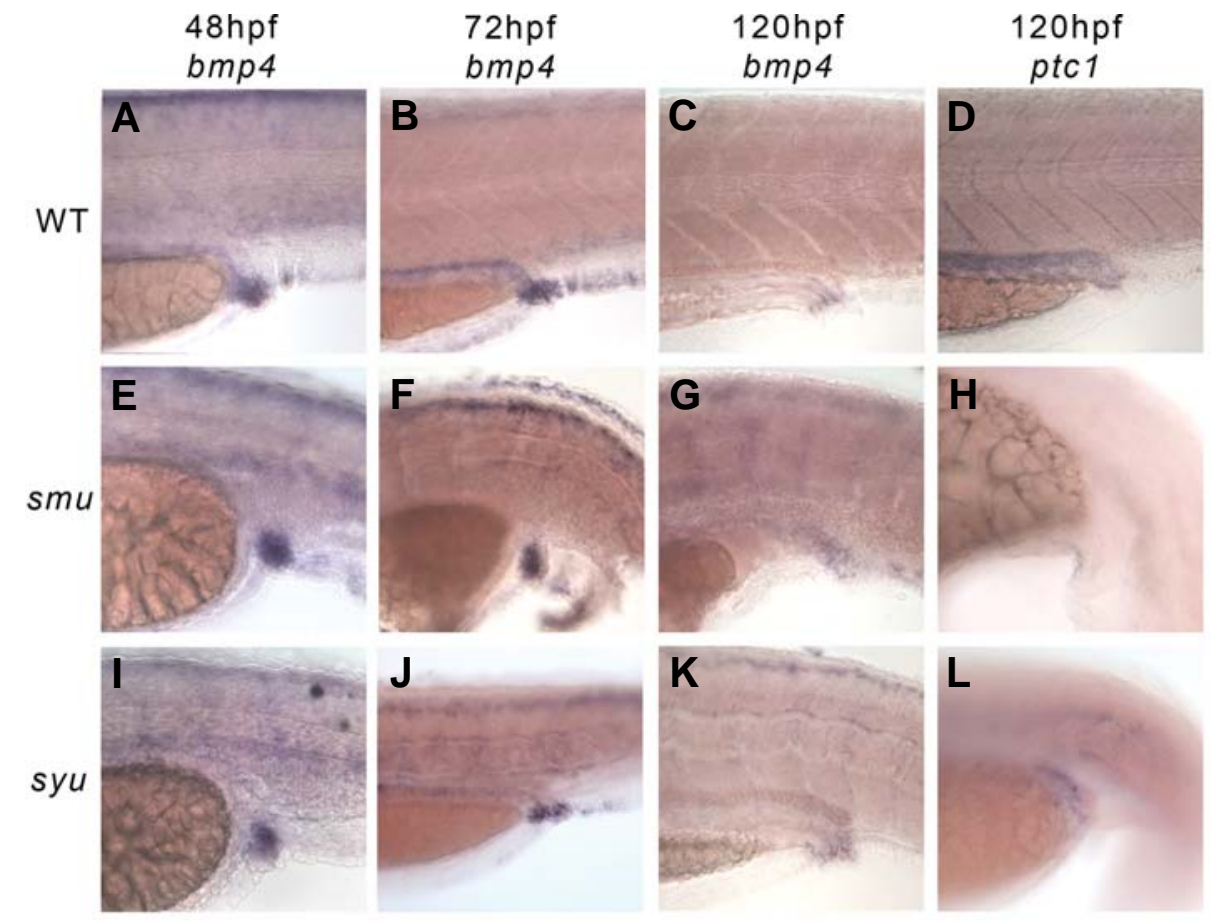

Fig. 4. Expression of putative $\boldsymbol{H h}$ target genes in $\mathbf{H h}$ mutants. Bmp4 and ptc1 expression in Hh pathway mutants and WT siblings. (A-C) WT siblings, 48, 72 and 120 hpf. bmp4 is diffusely expressed in the proctodeum and posterior gut. By $120 \mathrm{hpf}$ expression is restricted to the anus. (D) ptc1 expression in mesenchyme surrounding the posterior gut in a WT sibling. (E-G) smu, 48, 72, $120 \mathrm{hpf}$. Although the morphological defects in the smu posterior gut alter the shape of the bmp4 expression domain, there are no changes in the levels expressed. $\mathbf{( H )}$ There is no ptc1 expression around the cloacal region with the loss of all Hh signal transduction in the smu mutant. (I-K) syu, 48, 72, $120 \mathrm{hpf}$. Expression of bmp4 in the syu mutant is little different to the WT siblings. (L) Some ptc1 expression surrounding the posterior gut remains after the loss of shha in syu mutants. 
$7 \mathrm{H})$. Just over half the embryos in this treatment window were perforate (10/18) and over half of these embryos (6/10) displayed a fistula (6/18 of total embryos). The remaining $44 \%$ (8/ 18) of embryos had an imperforate anus and although half of these embryos had a fistula to the pronephric duct (4/8), there was no ejection of fluorescein into the surrounding water (Fig. 7H). Embryos treated between 48-74 hpf and 48-96 hpf also exhibited a large number of fistulas and atresia (Fig. 7I-L; data for 48-74hpf not shown). The fistulas occurred close to the correct anorectal opening such that there was no long, single channel composed of both posterior gut and pronephric duct, a phenotype that is frequently observed in syu mutant embryos and those treated with cyclopamine at earlier timepoints (Fig. 3I, K, 7A-H). In all embryos treated before $96 \mathrm{hpf}$, the proctodeum failed to adopt its distinctive upturned U-shape. A later treatment between 74 and 96 hpf resulted in no obvious ARM, although when examined with A-PI staining, compared to WT the urorectal area was somewhat disorganised (compare Fig. $3 \mathrm{~A}-\mathrm{C}$ with Fig. 7M-O). Fluorescein injections demonstrated that the posterior gastrointestinal tract was perforate in most cases (18/20; Fig. 6T). There was, however, some stenosis, a quarter of the embryos having a narrow anorectum (5/20).

Treatment of embryos with $5 \mu \mathrm{M}$ cyclopamine from 24 or 48 hpf resulted in malformed proctodeums and atresia (5/15), or in two cases apparent fistulas to the pronephric ducts $(2 / 15)$, similar to embryos treated with $25 \mu \mathrm{M}$ of cyclopamine. There were no ARMs in embryos treated with $5 \mu \mathrm{M}$ cyclopamine from $72 \mathrm{hpf}$.

\section{Defects in the notochord and floorplate do not disrupt anorectal development}

Since Hh proteins can act over many cell diameters, distantly located Hhexpressing tissues may have an impact on posterior gut development (Gritli-Linde et al., 2001). Overlying the gut during its development are the notochord and floorplate. shha is expressed in the notochord and medial floorplate (MFP) (Krauss et al., 1993), whilst shhb is expressed in the MFP (Ekker et al., 1995) and ihhb is expressed solely in the notochord (Currie and Ingham, 1996). ihhb and shhb expression in the MFP and notochord is lost by around 24 hpf.

To determine whether $\mathrm{Hh}$ proteins, or indeed other signalling molecules emanating from the axial midline structures of the embryo are required for the correct development of the urorectum, several mutants that disrupt the notochord and/or floorplate were studied.

In no tail (ntt tc41) mutant embryos the tail does not form and the notochord is completely missing from the posterior part of the embryo (and therefore shha expression is reduced to the MFP), yet despite these defects most embryos have a functional gastrointestinal tract (11/12; Fig. 8A-D). greatly reduced floor plate. Despite the loss of nearly
Zebrafish floating head (flh) mutants lack a notochord and are severely truncated, resembling $n t$ I mutants (Talbot et al., 1995). However, in addition to never developing a notochord they also have a all midline (excluding the gut) $\mathrm{Hh}$ expression

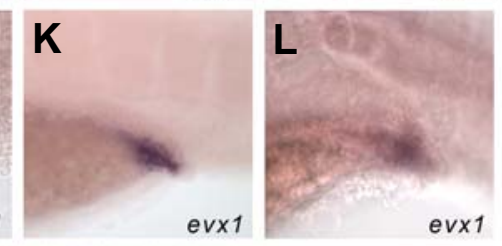

Fig. 5. evx1 and prdm 1 expression in the cloaca of Hh pathway mutant embryos. (A-D, M-O) WT sibling, 24-120 hpf. At 24 hpf evx1 and prdm1 are expressed in the proctodeum and caudal pronephros. They may also be expressed in the posterior gut at this stage, but it is difficult to determine the presence of endoderm in this area at 24hpf. Expression marked by the arrow may be the proctodeal tissue that fuses with the gastrointestinal tract. Expression in the proctodeum/cloaca is maintained until at least 120hpf. (E-F, P-R) smu, 24-120hpf. Despite morphological changes to the proctodeum and cloaca expression of evx1 and prdm1 are maintained. The altered shape of the expression domain appears to reflect the change in shape of the cloaca seen in live embryos but not a loss of the tissue itself. At 24 hpf-prdm 1 expression is not detectable in the putative posterior gut (arrow) whereas evx 1 expression is normal. Prdm 1 expression in the epidermis persists past 24 hpf in smu mutants (asterix) but not in WT siblings, suggesting that prdm 1 is regulated by Hh activity in the epidermis, but not the procotdeum. (I-L, S-U) syu, 24-120hpf. Expression of "evx1 and prdm1 are maintained in the cloaca of syu mutants. At $24 \mathrm{hpf}$ the expression of evx1 appears to be weaker than the WT siblings, but at other time points is barely distinguishable from the siblings, whilstprdm 1 expression at 24 hpf is normal in syu. Like smu mutants prdm1 expression in the epidermis persists past 24 hpf (asterix). 
(Odenthal et al., 1996), the flh gastrointesitinal tract and pronephric ducts open in the correct position (31/31; Fig. $8 \mathrm{E}-\mathrm{H})$. Fluorescent dye is extruded normally in most mutants $(20 / 23$; Fig. $8 \mathrm{H}$ ). Although the pronephric ducts are not clearly visible in live embryos due to epidermal thickening of the ventral fins obscuring the view, examination with A-PI shows the pronephric ducts open normally and the anus is well formed (Fig. $8 \mathrm{G})$.

Several other mutations affecting notochord development were investigated: doc, bashful (bal), sleepy (sly, data not shown) and crash test dummy (ctd). Embryos homozygous for all of these mutations, except $c t d$, have a short body axis, with reduced mesoderm in the tail. Nearly all the notochord and floorplate mutants studied develop functional digestive systems with perforate anus. As with WT embryos, a small number of embryos exhibited imperforate anus, but the presence of these anorectal abnormalities was not correlated with the severity of the notochord phenotype.

In the bal and doc mutant embryos, the notochord is mostly absent, although some vacuolated cells are present. This variability provides a basis for investigating the local requirement for notochord. The digestive tract, including the anorectum, is not visibly different between regions where the notochord is present and the regions from which it is absent (Fig. 8I-L).

In ctd mutant embryos the digestive system and urorectal opening develops normally. The notochord in ctd mutants undulates, which means that in some instances the notochord is closer to the digestive tract then in WT embryos. The juxta-

position of the notochord next to the digestive tract, at any anterior-posterior level, does not lead to morphological changes in the anus or the digestive tract (14/14; Fig. $8 M, N)$.

\section{Ectopic floorplate does not affect posterior gut develop- ment but changes in mesodermal movements affect the proctodeum}

Spadetail (spt) embryos have an expansion of notochord markers, including shha (Amacher et al., 2002). The medial floorplate in spt embryos is also wider, leading to an overall increase in midline $\mathrm{Hh}$ signalling (Griffin et al., 1998). The expansion of $\mathrm{Hh}$ expressing tissue resembles the effects seen in the Adriamycin rat model, in which the notochord is often bifurcated, producing an overall increase in Hh expression at the midline (Gillick et al., 2003). As a result of the floor plate expansion in spt mutants, the mesoderm and its derivatives are variably affected - often the pronephros fails to form properly and may not reach the urorectal opening (6/12; Fig. 8O, P). Despite the effect on the pronephric ducts and the occasional bifurcation of the foregut, the posterior gut is always in the correct position and in most cases is functional, as evidenced by the excretion of fluorescein salt (41/42; Fig. 8R). Examination of embryos with A-PI staining revealed that, even without correctly positioned pronephric ducts, a perforate anus develops (3/3 lacking pronephric ducts; Fig. 8Q). The proctodeum in all spt mutants is, however, malformed, resulting in a wide gut opening (Fig. 8O, P). When pronephric ducts are present they appear at some distance from the anus, resulting in a 'spreadout' appearance to the urorectal area (Fig. 80, P).
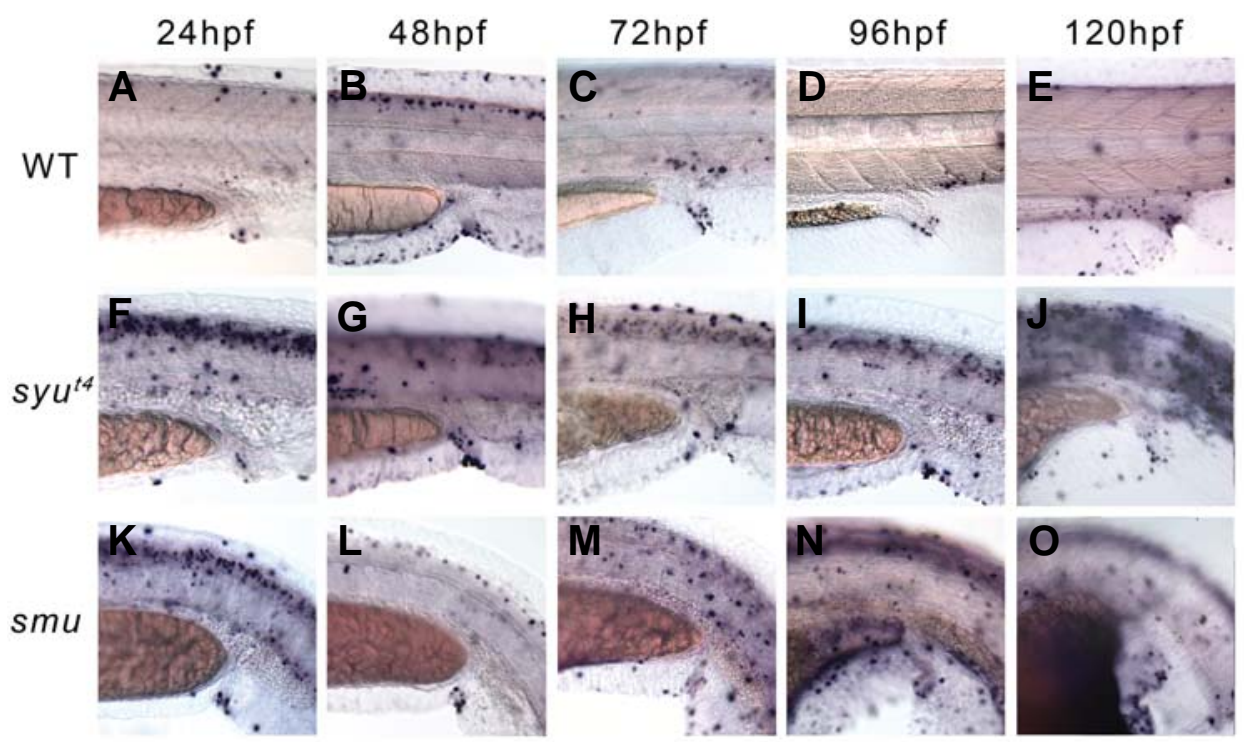

\section{Adriamycin does not cause ARMs in zebrafish}

Adriamycin (Doxorubicin Hydrochloride) is routinely used to induce ARMs in rats, though its mechanism of action is not well understood (Gutteridge and Halliwell, 2000). In the chick, Adriamycin has been shown to have no effect on the developing urorectum (Mortell etal., 2003). In the rat, the drug is administered peritoneally to the mother, whilst the chick is exposed directly to the drug, either through an airsac or albumin injection.

As zebrafish embryos develop externally, drug treatments can be administered directly, either by injection or soaking. We used both methods to

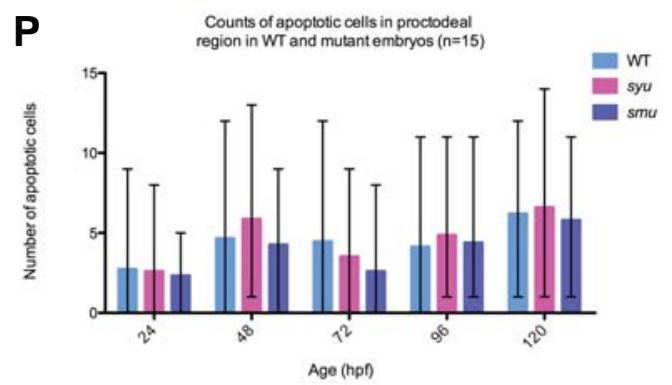

Fig. 6. Apoptotic events in the developing posterior gut of wild type and $\mathbf{H h}$ pathway mutants. (A-E) TUNEL staining of WT embryos between 24-120 hpf reveals the normal pattern of apoptosis during the formation of the posterior gut and pronephric ducts. At 120 hpf a number of cells in the cloaca die creating an externally opening posterior gut. (F-J) TUNEL staining of syu mutant between 24-120 hpf. (KO) TUNEL staining of smu mutants between 24-120 hpf. (P) Counts of apoptotic cells in the mutants and WT siblings reveals that there are large differences in the amount of cell death between embryos of the same age. However, there is no significant difference between the number of apoptotic cells in WT siblings and mutant embryos. 


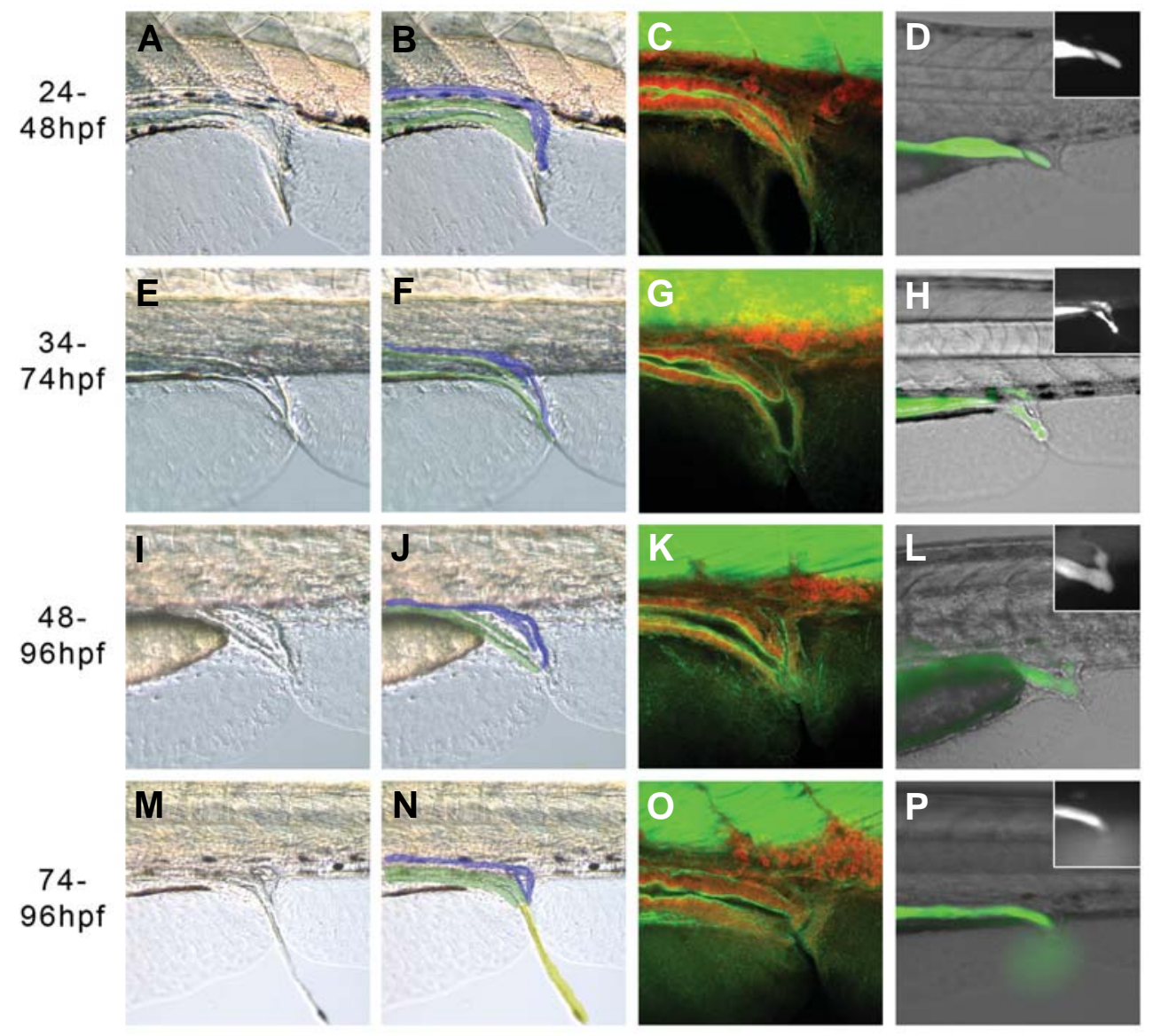

Fig. 7. Hh signalling is required between 48-74 hpf for the development of a perforate anus. Embryos treated with $25 \mu \mathrm{M}$ cyclopmine and imaged live at $120 \mathrm{hpf}$ with bright field illumination, $(\mathbf{A}, \mathbf{B}, \mathbf{E}, \mathbf{F}$, $\mathbf{I}, \mathbf{J}, \mathbf{M}, \mathbf{N})$ or by confocal microscopy following staining with $\alpha$-actin-phalloidin (green) and propidium iodide (red)

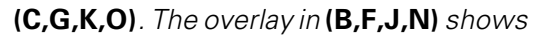
the approximate identity of the relevant tissues, with the posterior gut in green and pronephric ducts in blue. $(\mathbf{D}, \mathbf{H}, \mathbf{L}, \mathbf{P})$ Merged brightfield/fluorecent images of live embryos injected with fluorescein salt at 72-96 hpf, with the fluorescent channel only shown in the inset. (A,B) After treatment from 24-48 hpf, the posterior gut is thinner than in WT embryos, and despite the appearance of a fistula (C), the majority of embryos have a perforate gut, while $33 \%(4 / 12)$ were imperforate and the dye stayed in the blind ended posterior gut (D). (E-H) 34-74 hpf treatment. The posterior gut formed a fistula with the pronephric duct in most embryos, which allowed excretion through a single opening in the proctodeum in around half the embryos (10/18). In the embryos that were not perforate, fluorescein entered the pronephros, but could not be excreted and so moved anteriorly through the pronephric tubes, due to peristaltic pressure (H). (I-L) 48-74hpf treatment. Embryos from this treatment window had a range of phenotypes, 67\% (16/24) were perforate, but around half had a fistula to the pronephros (14/24), which itself was not always perforate leading to fluorescein in the pronephric ducts (L). Other embryos had atresia or stenosis. (M-P) 74-96 hpf treatment. The majority of embryos are perforate (90\%, 18/20 and the posterior gut musculature affords some control over the excretion of faecal matter. (P) Faecal matter being expelled in a live embryo.

expose embryos to Adriamycin. Injections at the 1-4 cell stage did not cause any defects in the embryos (data not shown). Embryos soaked in Adriamycin from the 1-4 cell stage until 120 hpf also exhibited no malformations (data not shown). At the very highest doses of Adriamycin $(300 \mu \mathrm{M})$ the embryos began to disintegrate at $24 \mathrm{hpf}$, presumably due to non specific toxicity. All the embryos that were soaked in Adriamycin had red intestinal lumens, indicating that the drug was being efficiently taken up. Since Adriamycin fluoresces, embryos that were either injected or soaked in the drug fluoresced brightly under UV light, indicating the drug was present in all the tissues, not just the gastrointestinal tract.

\section{Discussion}

\section{Hh signalling is essential for anorectal development in the zebrafish}

We have shown that, similar to the mouse (Mo et al., 2001) zebrafish cloacal development is dependent on Hh activity. Embryos lacking all Hh pathway activity, such as those mutant for smu or treated with cyclopamine, display the most severe ARMs. Embryos lacking shha activity alone have strong malformations that resemble those found in Shh mutant mice (Mo et al., 2001). The atresia seen in smu and some syu mutants resembles the phenotype of Fgf10 mutant mice, whereby the mutants have a relatively normal urogenital tract but the rectum does not fuse with the proctodeum and instead ends blindly (Fairbanks et al., 2004). One would expect Smo mutant mice to resemble closely those lacking Shh or Fgf10, however, an anorectal phenotype has not been described, presumably because Smo mutant embryos die very early in development (9.5 days post coitum) (Zhang et al., 2001), before the gut has fully formed.

Understanding how ARMS develop requires a knowledge of how the urorectal area normally develops; however, the mechanism by which the mammalian cloaca forms the urorectal sinus and anal canal is still a contentious issue (Sasaki et al., 2004a). The external development of zebrafish embryos allows the urorectal area to be examined in vivo as it matures. The lack of understanding of mammalian development means, however, that direct comparisons of how ARMS arise morphologically in fish and mammals is difficult, although this study demonstrates that the genetic pathways involved are conserved.

In zebrafish the presumptive cloaca or proctodeum forms from a single vacuolated cell, to which the pronephros fuses first, followed by the later developing posterior gut (Pyati et al., 2006). The gut and pronephros have discrete openings into the cloaca, which starts out as an upturned U-shape and then 
spreads out to open up at the edge of the ventral fins. The presence of apoptotic cells in this region suggests that cell death shapes the opening of the cloaca. The ARMs arising from perturbed $\mathrm{Hh}$ activity appear to affect the morphological development of the cloaca rather than the regulation of apoptosis in the area, as there is no significant change in the number of apoptotic cells in the mutants.

In syu fish it seems that the proctodeum fails to 'spread out' in to an upturned U-shape, causing the posterior gut to become continuous with the most distal part of the pronephros. If this is the mechanism causing the ARMs in syu embryos then the defect cannot really be classed as a fistula as it is not a 'channel' per se, although the result is the same. the gut and pronephros share a common cavity. In smumutants, the posterior gut fails to canalise completely, resulting in atresia. However, it is unclear whether this failure is within the gut endoderm, or in the proctodeal component of the cloaca, which would normally invaginate to meet and fuse with the advancing gastrointestinal lumen, but fails to do so in smumutants. The proctodeum is still present in smumutants (Fig. 5) and seems to sustain its rostral expansion towards the posterior gut, suggesting the fusion itself fails (either from the proctodeal or gastrointestinal side, or both). In the absence of significant changes in the levels of apoptosis and putative $\mathrm{Hh}$ target gene expression in the procotdeum, the mechanism causing ARMs in the Hh mutants remains unclear.

The different phenotypes observed in embryos lacking only Shha activity as apposed to all Hh activity, in the syu and smu mutants respectively, suggests that another Hh protein contributes to the development of the anorectal area. However, the loss of the only other Hh gene expressed in the posterior gut, ihha, does not cause ARMs, and when lost in addition to shha does not cause a smu-like phenotype (data not shown). This suggests another $\mathrm{Hh}$ signal is active in the area. Shhb is expressed in the anterior gastrointestinal tract, and it may be that low level expression extends posteriorly in syumutants, or that $d h h$, which is detectable by RT-PCR, but not in situ hybridization is expressed in the urorectal area (Avaron et al., 2006).

\section{High levels of Hh activity are necessary for correct anorec- tal development but the notochord is not required to pro- vide a source of Hh protein}

Studies using Adriamycin or ENU rat models of ARMs have suggested that the notochord abnormalities induced by these teratogens underlie the anorectal defects seen in treated animals (Arsic et al., 2004, Gillick et al., 2003, Mortell et al., 2004, Qi et al., 2003). It has also been suggested that the ectopic notochord would lead to a relative increase in Shh signalling, which may be responsible for the ARMs seen in these models (Arsic et al., 2004, Mortell et al., 2004). Since Hh proteins can act as morphogens, eliciting differing responses in target cells as a function of their concentration (Ericson et al., 1997, Ingham and

Fig. 8. Anal development in mutants with disrupted notochords. Brightfield images of live embryos $(\mathbf{A}, \mathbf{B}, \mathbf{E}, \mathbf{F}, \mathbf{H}, \mathbf{I}, \mathbf{L}, \mathbf{M})$ and confocal scans of embryos stained with $\alpha$-actin-phalloidin (green) and propidium iodide (red) at 120 hpf $(\mathbf{C}, \mathbf{G}, \mathbf{0})$. Live embryos were injected with fluorescein salt at 72 hpf,. Brightfield/fluorecent image merge with the fluorescent channel only shown in the inset $(\mathbf{D}, \mathbf{H}, \mathbf{R})$. The overlay in $(\mathbf{B}, \mathbf{F}, \mathbf{J}, \mathbf{L}, \mathbf{N}, \mathbf{P})$ shows the approximate identity of the relevant tissues, with the posterior gut in green and pronephric ducts in blue. (A-D) $\mathrm{ntl}$ embryos have normal pronephric ducts that open adjacent to the posterior gut. The posterior gut is much thicker in both $\mathrm{ntl}$ alleles, but still opens with a normal sized orifice (91\% perforate, n11/12). (E-H) flh mutant embryos develop a perforate anus and pronephric duct, which open independently of one another. $187 \%$ perforate, n20/23). (I-L) The presence or absence of a notochord near the urogenital opening does not affect its development in bal and doc embryos, which develop a functional anus. (M,N) ctd embryos develop a normal anus and pronephric opening despite undulations in the notochord close to the anus. (O-R) spt embryos have varying pronephric defects, and in some cases lack them altogether; even in the absence of the pronephros las shown here) the development of the posterior gut is relatively unperturbed (95\% perforate, 40/42), although the anal sphincter appears to be absent in most embryos $(\mathbf{A}, \mathbf{B}, \mathbf{E}, \mathbf{F}, \mathbf{I}, \mathbf{J}, \mathbf{Q}, \mathbf{R})$ black arrows mark the visible ejection of faecal matter from the anus. 
Fietz, 1995, Struhl et al., 1997) proposals that axial midline derived $\mathrm{H}$ h activity is required for anorectal development would imply that the target tissues respond to a low dose of Hhs, as the urorectal area is some distance from the notochord. Two lines of evidence presented here indicate that the notochord is dispensable for anorectal development and that high levels of $\mathrm{Hh}$ activity are required for normal development.

The various phenotypes of the three syualleles and the smu mutant appear to reflect an increase in severity of ARMs with decreasing levels of $\mathrm{Hh}$ activity - suggesting that the levels of Hh activity are critical for posterior gut development. High levels are essential for normal development, although at lower levels some aspects of anorectal development are able to proceed. This interpretation is supported by the development of imperforate and stenotic anus in many of the embryos treated with very low levels of cyclopamine. Five $\mu \mathrm{m}$ of cyclopamine was previously shown to be sufficient to inhibit only the highest levels of Hh signalling in the somites (Wolff et al., 2003). If any of the $\mathrm{Hh}$ signalling required for normal anorectal development originates from the midline than we would have expected to see ARMs in the mutants with reduced notochord and/or floorplate similar to those seen in low-dose cyclopamine treated embryos. The loss of $\mathrm{Hh}$ signals emanating from the midline should have reduced the total amount of activity in the urorectum if it were normally signalling to the gut, yet none of these mutants have significant ARMs, demonstrating that midline Hh signalling is dispensable for anorectal development.

It is also possible that the notochord is not involved in the formation of ARMs in other animals. The ARMs seen in zebrafish $\mathrm{Hh}$ mutants closely resemble those seen in mice and rats, and even humans. The hindgut is also a source of Hh signalling in these species and so it is very likely that some of the ARMs are induced by changes in $\mathrm{Hh}$ expression in the hindgut itself.

Interestingly, the increase in $\mathrm{Hh}$ activity occuring in the spt mutant did not cause anorectal defects resembling the ARMs seen in Adriamycin and ENU treated rats, in which Hh activity is postulated to be increased. Other studies investigating the nature of oesophageal and tracheal deformities in Adriamycin exposed embryos have suggested that changes in Shhexpression in the foregut itself are responsible for these defects (Arsic et al., 2004, Arsic et al., 2003, loannides et al., 2003) and oesophageal development is also perturbed in $\mathrm{Hh}$ deficient zebrafish embryos (Wallace and Pack, 2003). By analogy, it seems plausible changes in Hh expression in the posterior gut underlies the teratogen induced ARMs.

\section{Zebrafish gli mutants are comparable to those seen in amniotes}

The zebrafish gli1mutant, $d t r$, has a mostly WT posterior gut, with only a mild stenosis phenotype and the possible loss of the anal sphincter. Gli1 mouse mutants do not have ARMs (Mo et al., 2001), suggesting that Gli2a and Gli3 are able to compensate for the loss of Gli1, during posterior gut development, in both mouse and fish.

The zebrafish yot mutation generates a dominant repressor form of Gli2a, which results in a subsequent decrease in $\mathrm{Hh}$ target gene expression. Consistently, yot embryos have strong ARMs, with anal atresia or anal stenosis. gli2a transcripts are detectable in the posterior gut during development, suggesting that it normally transcribes $\mathrm{Hh}$ target genes in this region.

In the mouse Gli2a is the major transcriptional activator. Gli2a mutant mice have imperforate anus, with either rectourethral or rectal-vaginal fistula (Mo et al., 2001). Both the fish and mouse mutations result in a decrease in Hh target transcription and exhibit similar phenotypes - although yot mutants lack the fistulas. It seems probable that $g / i 1$ and/or gli3are able partly to compensate for the dominant repressor actions of the mutant gliza in yot embryos.

Interestingly, the truncated protein generated by the yot mutation resembles the repressor form of Gli3 that leads to dominant Pallister-Hall syndrome in humans (Kang et al., 1997). Studies have shown that only a mutation in the middle region of the gene causes Pallister-Hall syndrome, mutations elsewhere generally cause Greig cephalopolysyndactyly syndrome (GCPS), which does not involve an anal phenotype (Johnston et al., 2005, Wang et al., 2000).

\section{Hh activity is specifically required between 36 and 72 hpf for posterior gut development}

The Smo antagonist, cyclopamine, was used to elucidate the temporal requirements for $\mathrm{Hh}$ signalling. Despite ihha being expressed from mid-somitogenesis and shha from $24 \mathrm{hpf}$, in the posterior gut region, cyclopamine treatment revealed that Hh pathway activity is not required before $34 \mathrm{hpf}$. This identifies distinct temporal requirements for Hh and BMP activity, as the latter is only required during early somitogenesis and the phenotypes of $\mathrm{Hh}$ and BMP impaired fish reflects this difference. The pronephric ducts, which initially share a common opening with the posterior gut in the presumptive cloaca are largely unaffected by a loss of $\mathrm{Hh}$ activity. This suggests that the defects are not due to mis-specification of the cloaca, and are distinct from the BMP dependent malformations described by Payati et al., 2006), which cause cyst-like swellings in the pronephric terminus as well as posterior gut atresia. Consistent with this the $H h$ mutant fish have normal bmp4 expression in the proctodeum and $p r d m 1$ and $e v \times 1$ - both of which are altered in the bmp deficient zebrafish - are also unaffected by reductions in $\mathrm{Hh}$ activity. The temporally controlled exposure to cyclopamine supports the conclusion that it is the loss of $\mathrm{Hh}$ signals within the posterior gut, and not non-specific changes in the embryo overall, that cause the ARMs seen in both cyclopamine treated fish and the Hh pathway mutants. Treatment with cyclopamine after $24 \mathrm{hpf}$ does not cause any curling of embryos typical of Hh mutants but does cause severe ARMs, ruling out the possibility that the latter is a secondary consequence of curling. Conversely, the relatively normal development of the posterior gut in embryos that are otherwise severely malformed following cyclopamine exposure prior to $24 \mathrm{hpf}$ demonstrates its independence of other $\mathrm{Hh}$ regulated processes.

\section{The zebrafish as a model for ARMs}

ARMs are a significant clinical problem. The incidence is relatively high and can require extensive surgery to provide a tolerable quality of life. Even with surgical intervention the outlook for those with more serious defects is poor and for those who respond well to surgery there is often a long-term follow up required, in addition to psychological damage (Bai et al., 2000, 
Hartman et al., 2004). Our studies provide new insights into the molecular bases of ARMs, and suggest a robust model system for future analysis of the genetic and teratogenic contributors to ARMs.

\section{Materials and Methods}

\section{Fish maintenance}

Zebrafish were raised and maintained in compliance with UK Home Office guidelines using standard laboratory practice at $28.5^{\circ} \mathrm{C}$ (Kimmel et al., 1995). Adult fish identified as heterozygous for specific mutant alleles were inter-crossed to generate homozygous progeny. Embryos were harvested synchronously; staging based on developmental time was verified by morphological features as described by Kimmel et al.,1995). Lines used included the mutants: sonic you ${ }^{t 4}$, syu ${ }^{b \times 392}$ and syu ba70 (shha) (Schauerte et al., 1998), (van Eeden et al., 1996); smoothened $^{b 577}$ (smu) (Barresi et al., 2000); dtr (gli1)(Karlstrom et al., 1996, Karlstrom et al., 2003); yot ty119 (gli2) (Karlstrom et al., 1999, Karlstrom et al., 1996, Karlstrom et al., 2003); ihha hu2131 (ZF models); spadetail (tbx 16) (Griffin et al., 1998); no tail( $n t$ l, Brachyury homolog) (Kimmel et al., 1989, Odenthal et al., 1996); doc (gene unknown) (Odenthal et al., 1996); bashful (lama1) (Karlstrom et al., 1996); sleepy (lamc1) (Karlstrom et al., 1996), (Parsons et al., 2002) and crash test dummy (ctd, gene unknown) (Odenthal et al., 1996); floating head (flh, a not homeobox gene) (Odenthal et al., 1996), (Talbot et al., 1995) .

\section{Live imaging}

Live embryos were anesthetised with Tricaine (MS222; pH7.0) and immersed in 3\% methylcellulose or in fish water and observed using a Zeiss Axioplan microscope. Images were acquired using a SPOT 14.2 colour mosaic camera (Diagnostic Instruments) and processed using Photoshop software (Adobe).

\section{Immunohistochemistry}

Embryos were whole-mount stained with $0.25 \mu \mathrm{M}$ FITC-phalloidin (Sigma) and propidium iodide (Vector; $1: 500 ; 1 \mathrm{mg} / \mathrm{ml}$ stock), mounted in Vectashield (Vector) and imaged with a Leica SP confocal microscope.

\section{Fluorescein injections}

$0.3 \mu \mathrm{g} / \mathrm{ml}$ fluorescein salt (Sigma 28803) was injected into the pericardial sac of anesthetised embryos between 48-96 hpf. Development was allowed to proceed for 24 hours. Accumulation and excretion of salt in and from the gut lumen was detected under a fluorescent microscope using a Hamamatsu C4742-95 camera and Open Lab software (Improvision).

\section{TUNEL}

Embryos were fixed for TUNEL staining at $24 \mathrm{hpf}, 48 \mathrm{hpf}, 72 \mathrm{hpf}, 96$ hpf and $120 \mathrm{hpf}$ in $4 \%$ paraformaldehyde for two hours at room temperature. TUNEL was performed as described in the manufacturers protocol (Intergen).

\section{Cyclopamine treatment}

Embryos were treated with cyclopamine as previously described (Chen et al., 2001). In summary cyclopamine (Toronto Research Company) was dissolved in $95 \%$ ethanol to generate a $10 \mathrm{mM}$ stock solution and further diluted in embryo media to the appropriate working concentration. Three 10 minute washes in $50 \mathrm{ml}$ of PBS were used to remove cyclopamine from embryos when necessary before fixing, photographing or allowing development to proceed.

\section{Whole-mount in situ hybridisation}

In situ hybridisation was performed as previously described (Begemann and Ingham, 2000). Probes used have been described previously: shha(Krauss etal., 1993), ihha(Qiao, 1996) ptc1(Concordet et al., 1996), gli2a (Karlstrom et al., 1999), bmp4 (Hwang et al., 1997), prdm1 (Baxendale et al., 2004) and evx1 (Thaeron et al., 2000).

\section{Acknowledgements}

We thank L. Gleadall, S. Surfleet, F. Browne and M. Green for expert zebrafish husbandry. This work was supported by a UK MRC Postgraduate studentship and Centre Development Grant (G0400100) to PWI and by the Agency for Science Technology and Research (A*STAR) Singapore.

\section{References}

AMACHER, S.L., DRAPER, B.W., SUMMERS, B.R. and KIMMEL, C.B. (2002). The zebrafish T-box genes no tailand spadetailare required for development of trunk and tail mesoderm and medial floor plate. Development 129: 33113323.

ARSIC, D., CAMERON, V., ELLMERS, L., QUAN, Q.B., KEENAN, J. and BEASLEY, S. (2004). Adriamycin disruption of the Shh-Gli pathway is associated with abnormalities of foregut development. J Pediatr Surg 39: 17471753.

ARSIC, D., KEENAN, J., QUAN, Q.B. and BEASLEY, S. (2003). Differences in the levels of Sonic hedgehog protein during early foregut development caused by exposure to Adriamycin give clues to the role of the Shh gene in oesophageal atresia. Pediatr Surg Int 19: 463-466.

AVARON, F., HOFFMAN, L., GUAY, D. and AKIMENKO, M.A. (2006). Characterization of two new zebrafish members of the hedgehog family: atypical expression of a zebrafish indian hedgehoggene in skeletal elements of both endochondral and dermal origins. Dev Dyn 235: 478-489.

BAI, Y., YUAN, Z., WANG, W., ZHAO, Y. and WANG, H. (2000). Quality of life for children with fecal incontinence after surgically corrected anorectal malformation. J Pediatr Surg 35: 462-464.

BARRESI, M.J., STICKNEY, H.L. and DEVOTO, S.H. (2000). The zebrafish slow-muscle-omittedgene product is required for Hedgehog signal transduction and the development of slow muscle identity. Development 127: 21892199.

BAXENDALE, S., DAVISON, C., MUXWORTHY, C., WOLFF, C., INGHAM, P.W. and ROY, S. (2004). The B-cell maturation factor Blimp-1 specifies vertebrate slow-twitch muscle fiber identity in response to Hedgehog signaling. Nat Genet 36: 88-93.

BEGEMANN, G. and INGHAM, P.W. (2000). Developmental regulation of Tbx5 in zebrafish embryogenesis. Mech Dev 90: 299-304.

Belloni, E., MARTucciello, G., Verderio, D., PONTI, E., SeRI, M., JASONNI, V., TORRE, M., FERRARI, M., TSUI, L.C. and SCHERER, S.W. (2000). Involvement of the $H L X B 9$ homeobox gene in Currarino syndrome. Am J Hum Genet 66: 312-319.

BITGOOD, M.J. and MCMAHON, A.P. (1995). Hedgehog and Bmp genes are coexpressed at many diverse sites of cell-cell interaction in the mouse embryo. Dev Biol172: 126-138.

CHEN, W., BURGESS, S. and HOPKINS, N. (2001). Analysis of the zebrafish smoothenedmutant reveals conserved and divergent functions of hedgehog activity. Development 128: 2385-2396.

CONCORDET, J.P., LEWIS, K.E., MOORE, J.W., GOODRICH, L.V., JOHNSON, R.L., SCOTT, M.P. and INGHAM, P.W. (1996). Spatial regulation of a zebrafish patched homologue reflects the roles of sonic hedgehog and protein kinase A in neural tube and somite patterning. Development 122: 2835-2846.

CURRIE, P.D. and INGHAM, P.W. (1996). Induction of a specific muscle cell type by a hedgehog-like protein in zebrafish. Nature 382: 452-455.

EKKER, S.C., UNGAR, A.R., GREENSTEIN, P., VON KESSLER, D.P., PORTER, J.A., MOON, R.T. and BEACHY, P.A. (1995). Patterning activities of vertebrate hedgehog proteins in the developing eye and brain. Curr Bio/5: 944-955.

ERICSON, J., BRISCOE, J., RASHBASS, P., VAN HEYNINGEN, V. and JESSELL, T.M. (1997). Graded sonic hedgehog signaling and the specification of cell fate in the ventral neural tube. Cold Spring Harb Symp Quant Bio/62: 451-466.

FAIRBANKS, T.J., DE LANGHE, S., SALA, F.G., WARBURTON, D., ANDER- 
SON, K.D., BELLUSCI, S. and BURNS, R.C. (2004). Fibroblast growth factor 10 (Fgf10) invalidation results in anorectal malformation in mice. J Pediatr Surg 39: 360-365; discussion 360-365.

FIELD, H.A., OBER, E.A., ROESER, T. and STAINIER, D.Y. (2003). Formation of the digestive system in zebrafish. I. Liver morphogenesis. Dev Bio/253: 279-290.

GILLICK, J., MOONEY, E., GILES, S., BANNIGAN, J. and PURI, P. (2003). Notochord anomalies in the adriamycin rat model: A morphologic and molecular basis for the VACTERL association. J Pediatr Surg 38: 469-473; discussion 469-473.

GRIFFIN, K.J., AMACHER, S.L., KIMMEL, C.B. and KIMELMAN, D. (1998). Molecular identification of spadetait. regulation of zebrafish trunk and tail mesoderm formation by T-box genes. Development 125: 3379-3388.

GRITLI-LINDE, A., LEWIS, P., MCMAHON, A.P. and LINDE, A. (2001). The whereabouts of a morphogen: direct evidence for short- and graded longrange activity of hedgehog signaling peptides. Dev Bio/236: 364-386.

GUTTERIDGE, J.M. and HALLIWELL, B. (2000). Free radicals and antioxidants in the year 2000. A historical look to the future. Ann N Y Acad Sci899: 136147.

HAGAN, D.M., ROSS, A.J., STRACHAN, T., LYNCH, S.A., RUIZ-PEREZ, V., WANG, Y.M., SCAMBLER, P., CUSTARD, E., REARDON, W., HASSAN, S. et al. (2000). Mutation analysis and embryonic expression of the HLXB9 Currarino syndrome gene. Am J Hum Genet 66: 1504-1515.

HALL, J.G., PALLISTER, P.D., CLARREN, S.K., BECKWITH, J.B., WIGLESWORTH, F.W., FRASER, F.C., CHO, S., BENKE, P.J. and REED S.D. (1980). Congenital hypothalamic hamartoblastoma, hypopituitarism, imperforate anus and postaxial polydactyly - a new syndrome? Part I: clinical, causal, and pathogenetic considerations. Am J Med Genet 7: 47-74.

HARAGUCHI, R., SUZUKI, K., MURAKAMI, R.,SAKAI, M., KAMIKAWA, M. KENGAKU, M., SEKINE, K., KAWANO, H., KATO, S., UENO, N. and YAMADA, G. (2000) Molecular analysis of external genitalia formation: the role of fibroblast growth factor ( Fg $f$ genes during genital tubercle formation. Deve/opment 127: 2471-2479.

HARTMAN, E.E., OORT, F.J., ARONSON, D.C., HANNEMAN, M.J., VAN DER ZEE, D.C., RIEU, P.N., MADERN, G.C., DE LANGEN, Z.J., VAN HEURN, L.W., VAN SILFHOUT-BEZEMER, M. et al. (2004). Critical factors affecting quality of life of adult patients with anorectal malformations or Hirschsprung's disease. Am J Gastroentero/99: 907-913.

HWANG, S.P., TSOU, M.F., LIN, Y.C. and LIU, C.H. (1997). The zebrafish BMP4 gene: sequence analysis and expression pattern during embryonic development. DNA Cel/ Bio/16: 1003-1011.

INGHAM, P.W. and FIETZ, M.J. (1995). Quantitative effects of hedgehog and decapentaplegic activity on the patterning of the Drosophila wing. Curr Biol 5: $432-440$.

IOANNIDES, A.S., HENDERSON, D.J., SPITZ, L. and COPP, A.J. (2003). Role of Sonic hedgehog in the development of the trachea and oesophagus. $J$ Pediatr Surg 38: 29-36; discussion 29-36.

JOHNSTON, J.J., OLIVOS-GLANDER, I., KILLORAN, C., ELSON, E., TURNER J.T., PETERS, K.F., ABBOTT, M.H., AUGHTON, D.J., AYLSWORTH, A.S., BAMSHAD, M.J. et al. (2005). Molecular and clinical analyses of Greig cephalopolysyndactyly and Pallister-Hall syndromes: robust phenotype prediction from the type and position of GLI3 mutations. Am J Hum Genet 76: 609-622.

KANG, S., GRAHAM, J.M., JR., OLNEY, A.H. and BIESECKER, L.G. (1997). GLI3 frameshift mutations cause autosomal dominant Pallister-Hall syndrome. Nat Genet 15: 266-268.

KARLSTROM, R.O., TALBOT, W.S. and SCHIER, A.F. (1999). Comparative synteny cloning of zebrafish you-too: mutations in the Hedgehog target gli2 affect ventral forebrain patterning. Genes Dev 13: 388-393.

KARLSTROM, R.O., TROWE, T., KLOSTERMANN, S., BAIER, H., BRAND, M., CRAWFORD, A.D., GRUNEWALD, B., HAFFTER, P., HOFFMANN, H., MEYER, S.U. et al. (1996). Zebrafish mutations affecting retinotectal axon pathfinding. Development 123: 427-438.

KARLSTROM, R.O., TYURINA, O.V., KAWAKAMI, A., NISHIOKA, N., TALBOT, W.S., SASAKI, H. and SCHIER, A.F. (2003). Genetic analysis of zebrafish glit and gli2 reveals divergent requirements for gli genes in vertebrate development. Development 130: 1549-1564.
KIM, J., KIM, P. and HUI, C.C. (2001). The VACTERL association: lessons from the Sonic hedgehog pathway. Clin Genet 59: 306-315.

KIMMEL, C.B., BALLARD, W.W., KIMMEL, S.R., ULLMANN, B. and SCHILLING, T.F. (1995). Stages of embryonic development of the zebrafish. Dev Dyn203: 253-310.

KIMMEL, C.B., KANE, D.A., WALKER, C., WARGA, R.M. and ROTHMAN, M.B. (1989). A mutation that changes cell movement and cell fate in the zebrafish embryo. Nature 337: 358-362.

KIMMEL, S.G., MO, R., HUI, C.C. and KIM, P.C. (2000). New mouse models of congenital anorectal malformations. J Pediatr Surg 35: 227-230; discussion 230-221.

KOHLhASE, J., WISCHERMANN, A., REICHENBACH, H., FROSTER, U. and ENGEL, W. (1998). Mutations in the $S A L L 1$ putative transcription factor gene cause Townes-Brocks syndrome. Nat Genet 18: 81-83.

KOLKER, A.R., COOMBS, C.J., MEARA, J.G., BATES, D., ROWLER, D.K. and HUTSON, J.M. (2000). Patterns of radial dysmorphology with the VACTERL association in the adriamycin-exposed prenatal rat. Ann Plast Surg 45: 525530 .

KRAUSS, S., CONCORDET, J.P. and INGHAM, P.W. (1993). A functionally conserved homolog of the Drosophila segment polarity gene $h$ h is expressed in tissues with polarizing activity in zebrafish embryos. Ce//75: 1431-1444.

MARTINEZ-FRIAS, M.L., BERMEJO, E. and FRIAS, J.L. (2001). The VACTERL association: lessons from the Sonic hedgehog pathway. Clin Genet 60: $397-$ 398.

MILLAR, A.J., FOROOTAN, H. and RODE, H. (2001). An adriamycin experimental rat model inducing a wide variety of abnormalities similar to VACTERL association in humans is now well established. Pediatr Surg Int 17: 502.

MO, R., KIM, J.H., ZHANG, J., CHIANG, C., HUI, C.C. and KIM, P.C. (2001). Anorectal malformations caused by defects in sonic hedgehog signaling. $\mathrm{Am}$ J Pathol 159: 765-774.

MORTELL, A., GILES, J., BANNIGAN, J. and PURI, P. (2003). Adriamycin effects on the chick embryo. Pediatr Surg Int 19: 359-364.

MORTELL, A., O'DONNELL, A.M., GILES, S., BANNIGAN, J. and PURI, P. (2004). Adriamycin induces notochord hypertrophy with conservation of sonic hedgehog expression in abnormal ectopic notochord in the adriamycin rat model. J Pediatr Surg 39: 859-863

ODENTHAL, J., HAFFTER, P., VOGELSANG, E., BRAND, M., VAN EEDEN, F.J., FURUTANI-SEIKI, M., GRANATO, M., HAMMERSCHMIDT, M., HEISENBERG, C.P., JIANG, Y.J. et al. (1996). Mutations affecting the formation of the notochord in the zebrafish, Danio rerio. Development 123: 103-115.

PARSONS, M.J., POLLARD, S.M., SAUDE, L., FELDMAN, B., COUTINHO, P., HIRST, E.M. and STEMPLE, D.L. (2002). Zebrafish mutants identify an essential role for laminins in notochord formation. Development 129: 31373146.

PYATI, U.J., COOPER, M.S., DAVIDSON, A.J., NECHIPORUK, A. and KIMELMAN, D. (2006). Sustained Bmp signaling is essential for cloaca development in zebrafish. Development 133: 2275-2284.

QI, B.Q., BEASLEY, S.W. and FRIZELLE, F.A. (2003). Evidence that the notochord may be pivotal in the development of sacral and anorectal malformations. J Pediatr Surg 38: 1310-1316.

QIAO, T., (1997) The expression and function of spatially regulated genes in the zebrafish embryo. PhD Thesis, University of London

RAMALHO-SANTOS, M., MELTON, D.A. and MCMAHON, A.P. (2000). Hedgehog signals regulate multiple aspects of gastrointestinal development. Deve/opment 127: 2763-2772.

RITTLER, M., PAZ, J.E. and CASTILLA, E.E. (1996). VACTERL association, epidemiologic definition and delineation. Am J Med Genet 63: 529-536.

ROSS, A.J., RUIZ-PEREZ, V., WANG, Y., HAGAN, D.M., SCHERER, S., LYNCH, S.A., LINDSAY, S., CUSTARD, E., BELLONI, E., WILSON, D.I. et al. (1998). A homeobox gene, $H L X B 9$, is the major locus for dominantly inherited sacral agenesis. Nat Genet 20: 358-361.

ROY, S., QIAO, T., WOLFF, C. and INGHAM, P.W. (2001). Hedgehog signaling pathway is essential for pancreas specification in the zebrafish embryo. Curr Biol 11: 1358-1363.

SASAKI, C., YAMAGUCHI, K. and AKITA, K. (2004a). Spatiotemporal distribu- 
tion of apoptosis during normal cloacal development in mice. Anat Rec $A$ Discov Mol Cell Evol Biol279: 761-767.

SASAKI, Y., IWAI, N., TSUDA, T. and KIMURA, O. (2004b). Sonic hedgehog and bone morphogenetic protein 4 expressions in the hindgut region of murine embryos with anorectal malformations. J Pediatr Surg 39: 170-173; discussion 170-173.

SCHAUERTE, H.E., VAN EEDEN, F.J., FRICKE, C., ODENTHAL, J., STRAHLE, $U$. and HAFFTER, P. (1998). Sonic hedgehog is not required for the induction of medial floor plate cells in the zebrafish. Development 125: 2983-2993.

SPILDE, T., BHATIA, A., OSTLIE, D., MAROSKY, J., HOLCOMB, G., 3RD, SNYDER, C. and GITTES, G. (2003). A role for sonic hedgehog signaling in the pathogenesis of human tracheoesophageal fistula. J Pediatr Surg 38 : 465-468.

STRAHLE, U., BLADER, P. and INGHAM, P.W. (1996). Expression of axia/and sonic hedgehog in wildtype and midline defective zebrafish embryos. Int $J$ Dev Biol 40: 929-940.

STRUHL, G., BARBASH, D.A. and LAWRENCE, P.A. (1997). Hedgehog acts by distinct gradient and signal relay mechanisms to organise cell type and cell polarity in the Drosophila abdomen. Development 124: 2155-2165.

TALBOT, W.S., TREVARROW, B., HALPERN, M.E., MELBY, A.E., FARR, G., POSTLETHWAIT, J.H., JOWETT, T., KIMMEL, C.B. and KIMELMAN, D. (1995). A homeobox gene essential for zebrafish notochord development.
Nature 378: 150-157.

THAERON, C., AVARON, F., CASANE, D., BORDAY, V., THISSE, B., THISSE, C., BOULEKBACHE, H. and LAURENTI, P. (2000). Zebrafish evX1 is dynamically expressed during embryogenesis in subsets of interneurones, posterior gut and urogenital system. Mech Dev 99: 167-172.

VAN EEDEN, F.J., GRANATO, M., SCHACH, U., BRAND, M., FURUTANI-SEIKI, M., HAFFTER, P., HAMMERSCHMIDT, M., HEISENBERG, C.P., JIANG, Y.J., KANE, D.A. et al. (1996). Mutations affecting somite formation and patterning in the zebrafish, Danio rerio. Development 123: 153-164.

WALLACE, K.N. and PACK, M. (2003). Unique and conserved aspects of gut development in zebrafish. Dev Bio/255: 12-29.

WANG, B., FALLON, J.F. and BEACHY, P.A. (2000). Hedgehog-regulated processing of Gli3 produces an anterior/posterior repressor gradient in the developing vertebrate limb. Cel/100: 423-434.

WELLS, J.M. and MELTON, D.A. (1999). Vertebrate endoderm development. Annu Rev Cell Dev Biol 15: 393-410.

ZF-MODELS - Zebrafish Models for Human Development and Disease. http:// www.zf-models.org/

ZHANG, X.M., RAMALHO-SANTOS, M. and MCMAHON, A.P. (2001). Smoothened mutants reveal redundant roles for Shh and Ihh signaling including regulation of L/R symmetry by the mouse node. Cel/106: 781-792.

\section{Further Related Reading, published previously in the Int. J. Dev. Biol.}

See our recent Special Issue Fertilization, in honor of David L. Garbers and edited by Paul M. Wassarman and Victor D. Vacquier at: http://www.ijdb.ehu.es/web/contents.php?vol=52\&issue=5-6

Developmental genetics in Sheffield: a meeting point for Hedgehog researchers.

M Placzek and P W Ingham

Int. J. Dev. Biol. (2000) 44: 65-72

Expression of axial and sonic hedgehog in wildtype and midline defective zebrafish embryos.

U Strähle, P Blader and P W Ingham

Int. J. Dev. Biol. (1996) 40: 929-940

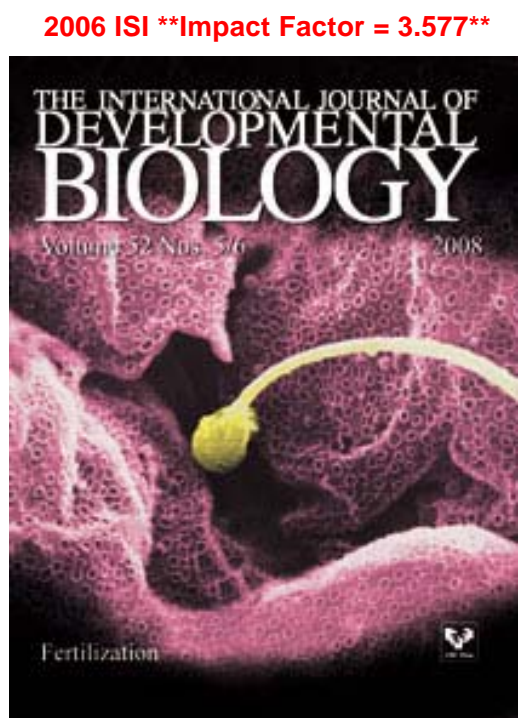

